\title{
Market Research on Gaps and Perennial Problems of Beauty Industry
}

\author{
Apar Gupta ${ }^{1 *}$, Nancy Chhabra ${ }^{2} \&$ Shamalu Mathew ${ }^{3}$ \\ ${ }^{1-3}$ Blu Ocean Innovations Private Limited, India. A company registered under the companies Act 2013, DPIIT recognized.
}

Copyright: (๑) 2021 Apar Gupta et al. This is an open access article distributed under the terms of the Creative Commons Attribution License, which permits unrestricted use, distribution, and reproduction in any medium, provided the original author and source are credited.

The word 'cosmetics' is taken from a Greek word "kosmeticos" which means to embellish. Sure, cosmetics make you look good, but just like al things too good to be true, the positive benefits of using such products can take a toll on your health. Since early days materials used for remodelling or improvement of presence comes under the category of cosmetics. People want to look beautiful and the concept of cosmetics is as old as mankind and development. The need to beautify one's own body and look beautiful has been a desire in the human race since the tribal days. Various beauty products such as skincare products, hair products, fragrances, oral hygiene, and nail products, which may contain toxic chemicals that can be destructive to health are used especially by women. Since long time cosmetics have been known to enhance the arrival of the human body. In a society obsessed with beauty, people are lured to fake their appearance as a cure for their insecurities the average woman uses 12 personal care products a day containing 168 different chemicals. A recent study has revealed that the skin may absorb up to 60 per cent of the chemicals in products it comes in contact with. But these products, which are imaginary to make us feel healthy and look beautiful, have a deep dark side. In our research analysis it is clearly depicting that most of the respondents are accepting that the advertisements, which are shown to us are purely the signs of marketing gimmicks. Various toxic ingredients and hazardous chemicals used in cosmetics are incorporated in beyond adequate limits. Cosmetics have not only seeped into the fashion world but are also playing a prominent role in one's day-to-day life. Thus, it becomes a necessity to make people aware of various harmful effects of cosmetics and chemicals used in cosmetics. But our main concern is on the Revamping or doing a makeover o beauty industry with respect to aesthetics. With this Mission to provide best products and services using the best and most advanced cutting-edge technologies, procured in a sustainable manner while respecting our environment, contributing to well-being of our consumers, and enriching their lives.

Keywords: Cosmetics, Marketing gimmicks, Cutting-edge technologies, Toxic chemicals.

\section{Introduction}

The wellness industry is going through a dark phase where there is a dying novelty and a drying pipeline towards innovations and remodeling. In light of wider societal, economic and technological shifts, impacting virtually every industry, the beauty market is one of the worst hit sectors due to current economic conditions. Successful brands are those that make their headway with respect to active listening and responding to the changing needs and demands of their customers. At the root of their success is an understanding of what today's beauty buyer expects from brands, and the changes they want to see across the beauty industry more generally. Also offering an explanation for recent developments in the modern beauty landscape, these shifting expectations indicate why the industry is still due a much-needed makeover. The beauty industry is known for catering to younger demographics, thereby tying our perception of beauty to youth. High growth prospectus and opportunities within the wellness industry have attracted a number of global and domestic new entrants and accelerated expansion plans of existing players. For instance, the salon and spa services segment has witnessed the entry of a number of global players. Rising income, increasing awareness among consumers Tier II and III regions and lower rental and manpower costs are some of the drivers. Consumer spend on beauty industry care continues to be resilient with a marginal slowdown in value growth. The organised market for salons has been growing at a much faster rate and currently to look good and the rising levels of awareness on its minimal side effects.

What's surprising, though, is the prevalence of this sentiment among millennial buyers (aged 23-36), 4 in 10 of whom share this opinion. Clearly there is a gap in the world of advertising that needs to be filled, and a call for the 
beauty industry to better celebrate novel concepts, to move beyond the Marketing gimmicks such as "Natural, herbal or organic".

A majority of beauty buyers agree that a brand's reputation is important when purchasing beauty products. Though factors such as Advertising, promotional activities, celebrity endorsements, etc. do affect the buying behavior but the vital information such as chemical contents, packaging material and other is left un noticed. The importance of knowledge such as how many carcinogens are present, how bio-physiological and hormone altering chemicals are present or compounds that may be hazardous to ecological/environment balance, aside being equally hazardous to human skin / body. After all, pollutants not only pollute the environment but your body as well.

The need to experiment and innovate better and sustainable beauty solutions grow as the industry gets crowded with hazardous brands, which are well marketed with saccharine coated endorsements. One explanation is for the rising demand for ingredient transparency as consumers are now slowly growing more alert towards the beauty products they use. With skin sensitivity and rising cases of skin and other malignancy related to harmful beauty products; fears of irritation becoming more common; about chemicals stripping away the body's natural oils; etc.

So, despite the recent explosion of organic skin care products, a large segment of beauty buyers still say they aren't satisfied with such brands and there is a big lacuna for a perfect beauty solution. The power of technology and the need for beauty enhancement procedures has given a tremendous push to aesthetic industry. It is ultimately going to be the change and future of beauty and wellness industry.

India's wellness industry is one of the fastest growing sectors today and with right application of technology, it shall not only enhance the capability but also improve the quality and efficiency of the industry.

It is intriguing to share that men and women alike, spend a decent proportion of their time and effort in maintaining their appearances. Market data reveals that the male to female ratio interested in aesthetic procedures is 1:1, in current scenario. Formerly driven by the female, the industry is finding a good proportion of men keeping themselves updated and educated about treatment options, costs and the outcomes involved.

\section{Existing flaws in beauty industry}

A digital payment system to counter all cash-based transactions. This shall also help in monitoring and tracking the growth of industry and plugging several loopholes. A same beauty service is offered at different prices at different Salons. We have provided a system where a customer can compare the prices for same service offered by the different salons and book the service accordingly.

Haircare services such as Keratin treatment may contain formaldehyde (which is a known carcinogen that is dangerous to both, salon clients and salon workers). We shall be providing services/products that are completely safe and doesn't affect the health of salon clients and workers in any adverse manner.

\section{Some interesting facts}

Sure, cosmetics make you look good, but just like all things too good to be true, the positive benefits of using such products can take a toll on your health. 
- According to studies, the average woman uses 12 personal care products a day containing 168 different chemicals. A recent study has revealed that the skin may absorb up to 60 per cent of the chemicals in products it comes in contact with.

- Another study, by the North western University School of Medicine in Evanston, Illinois, has also revealed that complaints made against beauty goods more than doubled from 2015 to 2016, with haircare products topping the list.

The most common chemical found in beauty products is paraben, which is used as preservative in deodorants, moisturisers, shampoos, body wash and makeup, and increases the chances of breast cancer. Its chemical structure is similar to estrogen and it can be carcinogenic even in tiny amounts.

There's also ethanolamine, which contains impurities like nitrosamines and is usually not listed on product labels. It's actually a respiratory, skin and organ cancer causing toxicants, and is usually found in soaps, shampoos, hair conditioners and dyes, shaving creams, eyeliners, mascara, fragrances and sunscreens.

\section{Review of literature}

This study adds to writing by concentrating on the major gaps and loopholes in beauty and wellness industry. The aim of literature reviews is to legitimize, method of reasoning of a guaranteeing research study, gives a review of verifiable viewpoints and to bring to the light the examination patterns and issues.

According to Dr Rachna Jagia, MD, DNB, DAAAM-USA; head and senior consultant, Venkateshwar Hospital, Dwarka, studied that "Beauty products may not impart the projected results. On the contrary, substandard quality, grade, harmful compositions can result in allergies, discolouration, texture alteration or permanent damage to the skin or hair. Increased usage and unregulated production have led to steep rise in side effects suffered by the consumers. She has seen the number of cases double, especially in the younger to middle aged patients".

Dr Rachna adds, "Used as an antimicrobial agent in personal care products, it can act as endocrine disruptor and disturb thyroid, testosterone and estrogen regulation, leading to issues like early puberty, poor sperm quality, infertility, obesity, and cancer. If children are exposed to this at an early age, they have an increased chance of developing allergies, asthma and eczema".

Dr Rachna adds, "Many fairness creams also contain steroids which cause skin damage, thinning, redness, colour alteration and acne, apart from hydroquinone or mercury, which have been associated with cancers".

According to Dr Rohit Batra, dermatologist, Sir Ganga Ram Hospital, and Derma World Skin and Hair Clinic, points out that phthalates, found in hair sprays and lotions may cause reproductive birth defects in males and females, liver/kidney/lung damage and cancer.

Dr Rohit adds, "When it comes to beauty products, less is better! You are likely to damage your skin more by using all these products. Opt for a routine body check-up and use good alternatives to beauty products like an organic face wash instead of a chemical one, pomegranate seeds instead of lip gloss, aloe vera gels as great moisturising agent and coconut oil instead of harmful body lotions". 


\section{AJAST}

Asian Journal of Applied Science and Technology (AJAST)

Volume 5, Issue 3, Pages 162-176, July-September 2021

Dr Rohit adds, "Choose products that are labelled noncomedogenic as that ensures the product doesn't cause skin irritation. Opt for products with fatty alcohols like cetyl, cetearyl, lanolin or stearyl alcohol which works as good moisturisers".

According to Campaign for safe cosmetics (2019) explored that Acrylates (ethyl acrylate, ethyl methacrylate, and methyl methacrylate) are ingredients found in artificial nail products (acrylic nails, nail enhancing polishes). Inhalation and skin contact are two main exposure routes. Despite evidence of adverse skin, eye, and throat reactions to these chemicals, they continue to be used in nail products.

According to Dr Amit Bangia, consultant dermatologist, Asian Institute of Medical Sciences, says that "Triclosan, found in most antibacterial soaps and deodorant, causes skin irritation and infection." Dr Amit adds, "The products shouldn't contain parabens, formaldehyde, fragrance, petroleum, AHA and BHA and phthalates. Use products which contain natural ingredients like rose petal, sandalwood and aloe vera. Avocado is an ultra-moisturising fatty fruit and contains vitamins A, D and E that are able to penetrate the skin. It helps soothe sunburn, can boost collagen production and treat age spots."

\section{Research Methodology}

Research Methodology is a way to systematically solve the research problem. It may be understood as a science of studying how research is done scientifically. In it we study the various steps that are generally adopted by a researcher in studying his research problem along with the logic behind them. It is necessary for the researcher to know not only the research methods/techniques but also the methodology. Researchers not only need to know how to develop certain indices or tests, how to calculate the mean, the mode, the median, or the standard deviation or chi-square, how to apply particular research techniques, but they also need to know which of these methods or techniques are relevant and which are not, and what would they mean and indicate and why. Researchers also need to understand the assumption underlying various techniques and they need to know the certain criteria by which they decide that certain techniques and procedures will be applicable to certain problems and other not.

\section{Objective of the study}

- To study and analyse the major gaps and loopholes in beauty and wellness industry.

- To study and analyse the customer's satisfaction level through customer profiling.

- To study in detail the Current gaps and pitfalls of beauty industry.

\section{The sample size}

A sample size is of 208 respondents considered sufficient for obtaining reliable data, covering PAN India.

\section{Sampling method}

A simple random sampling which means convenience basis covering primary respondents from major cities and metropolitans. Considering sample on basis of Customer demographics with a well-defined structured questionnaire for Primary respondents. 


\section{Methods of Data Collection}

1. Primary Data: Primary data are collected fresh $\&$ for the first time, especially for the designated study. We are Visiting Aesthetic centres, meeting owners and end customers.

a. Interview/Questionnaire method: -The data collected by presenting the stimuli to the respondents in the form of questions for eliciting appropriate responses from them. We did telephonic or Web based Interviews.

2. Secondary data collection: Our study is also based on secondary data, include information from the various books, internet, newspapers \& magazines etc.

\section{Analysis technique}

Analysis is to be evaluated by Qualitative analysis on MS EXCEL using tools like Cross-Tabulation, Pivot table etc. will be done to assess the association between various outcomes.

\section{Analysis}

This paper has been written to find out to what extent the major gaps and loopholes in beauty and wellness industry. We have Collected data from 208 respondents, also we have done Cross tabulation in our analysis.

Cross tabulations provide a way of analysing and comparing the results for one or more variables with the results of another (or others). In our research, mostly the survey results are presented in aggregate only - meaning, the data tables are based on the entire group of survey respondents.

In Our analysis is on market gimmicks on herbals advertisements and choices of a beauty salon or reason for going to the salon.

1) The first analysis is to identify the perception of respondents of market gimmicks on the herbal's advertisements.

With cross tabulation between the two variables i.e., one variable is Gender and another Is the advertisement that you see about natural herbals things are the market gimmicks or not for you?

Table 1. Perception of respondents to market gimmicks

\begin{tabular}{|l|c|c|c|}
\hline $\begin{array}{l}\text { Count of Is the advertisement that you see } \\
\text { about natural herbals things are the } \\
\text { marketgimmicks or not for you? }\end{array}$ & Column Labels & & \\
Row Labels & No & Yes & Grand Total \\
\hline Female & 26 & 88 & 114 \\
\hline Male & 21 & 73 & 94 \\
\hline Grand Total & 47 & 161 & 208 \\
\hline
\end{tabular}




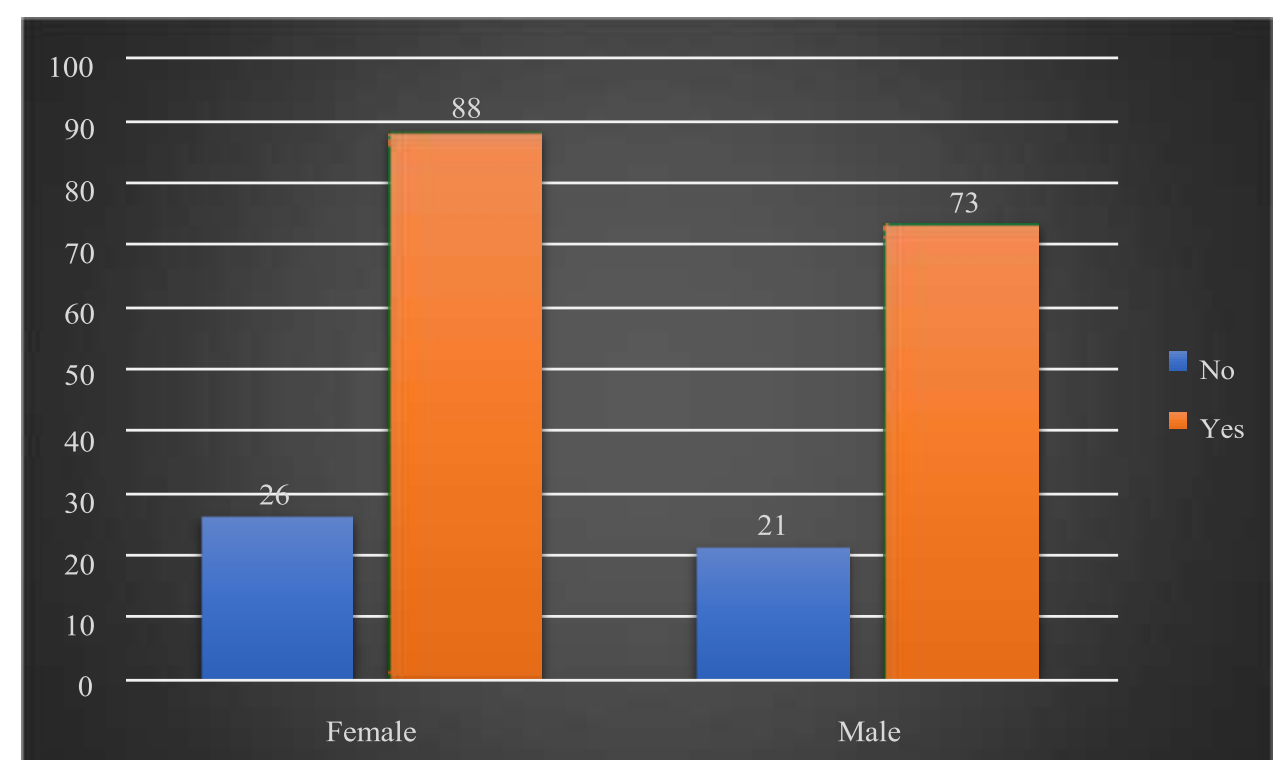

Graph 1. Perception of respondents to market gimmicks

From the above data it is clearly depicting that most of the respondents are accepting that the advertisements, which are shown to us are purely the signs of marketing gimmicks. Also, we come to the conclusion of ratio of 2:1 from the data.

\section{2) The second analysis is to identify what reason affect their choice of a beauty salon or reason for g4oing to the} salon and how they have been they are taking the services.

With cross tabulation between the two variables i.e., one variable is how long they are taking salon services and another what are the reasons for choices for their services.

This is the following reason affect their choices of a beauty salon or reason for going to the salon:-

$\checkmark$ Regular beauty rituals

$\checkmark$ Salon as the only beauty service provider

$\checkmark \quad$ Staff knowledge and skill about the various salon services

$\checkmark$ Quality of treatment

$\checkmark$ Interior of the salon is designed according to consumer convenience

$\checkmark$ Rapport with one or more-member staff

$\checkmark$ Awards and recognition salon have

$\checkmark$ Free services like Refreshment offered in a salon

$\checkmark$ The honesty of the salon

$\checkmark$ Location of salon

$\checkmark$ Payment system

$\checkmark$ Clean, tidy and well-ventilated salon 
Equipped with a noticeable signboard

$\checkmark$ Sufficient amount of staff

$\checkmark$ Smooth service process

$\checkmark$ Offer querying services and takes the appointment by phone

$\checkmark$ Friendly, polite and service-minded staff

$\checkmark$ Brand name, image, and reputation

$\checkmark$ Prices are reasonable according to the product / service quality

$\checkmark$ Services are according to international or government prescribed standards

$\checkmark$ Recommendation from friends and family

$\checkmark$ Birthday's/ anniversary gift cards

$\checkmark$ Discussion forums, beauty blogs

$\checkmark$ Consumer ratings on the internet

$\checkmark$ Website of the salon

$\checkmark$ Customized packages

$\checkmark$ Personal attention

$\checkmark$ Status symbol

$\checkmark$ Offers, discount coupons

$\checkmark$ Magazine recommendation

$\checkmark$ Advertisements

Table 2. Reasoning for the choice of beauty salon

\begin{tabular}{|l|c|c|c|c|}
\hline $\begin{array}{l}\text { Count of Which of the } \\
\text { following reason affect } \\
\text { your choice of a beauty } \\
\text { salon or reason for } \\
\text { going to the salon? } \\
\text { Row Labels }\end{array}$ & $\begin{array}{c}\text { Column Labels } \\
\text { treatment }\end{array}$ & $\begin{array}{r}\text { Salon as the only of } \\
\text { service provider }\end{array}$ & $\begin{array}{r}\text { Beauty staff knowledge } \\
\text { and skill about various } \\
\text { salon services }\end{array}$ & Grand Total \\
\hline 0-1 year & 4 & 2 & & \\
\hline 1-3 years & & 1 & & 10 \\
\hline 3-5 years & 2 & 3 & 6 & 1 \\
\hline More than 5 years & 6 & 6 & & \\
\hline Grand Total & & & & \\
\hline
\end{tabular}




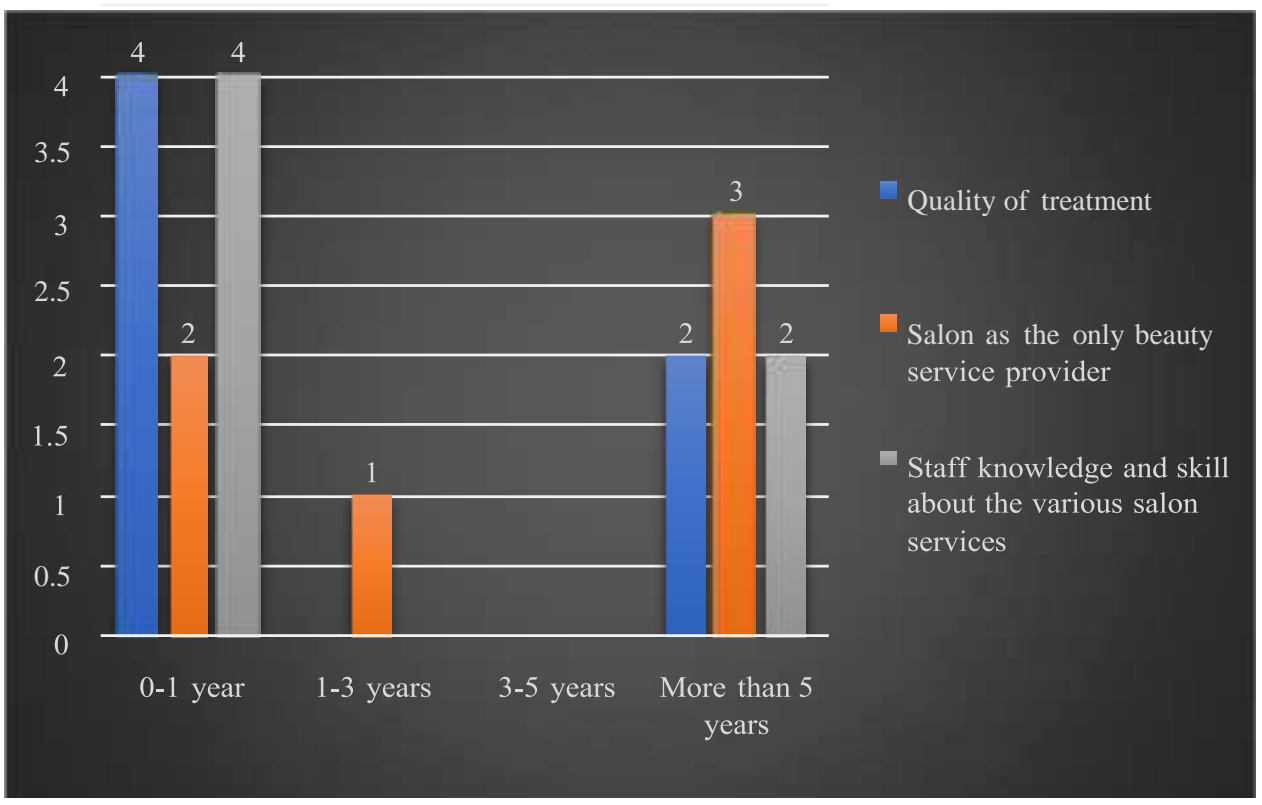

Graph 2. Reasoning for the choice of beauty salon

From the above data it is clearly depicting that from 0-1 to more than 5-year respondents who have been taking services are depicting that salon is the only solution for the beauty services, and this can be shown in our above analysis. We come to the conclusion that they are only depend on the salon for their beauty services, they are not aware about the chemicals and harmful products used on them.

\section{Results and Discussions}

We have done the survey with more than 200 people about the perception of Indian Salon industry in developing nations, there is a standard operative procedure for beauty services. How a service has to be done? What is the total duration of the service? what reason affect their choice of a beauty salon or reason for going to the salon and how they have been they are taking the services.? Is the advertisement that you see about natural herbals things are the market gimmicks or not for you? How a serum has to be applied, etc. Surprisingly, most of the service providers and clients are not aware of any allergic or highly reactive cosmetic ingredients. They are too casual in their approach. On the contrary, in developed countries the people are aware and know the cautious towards allergic reactions and consider all important precautions. When we enter in a salon, our eyes get attracted towards the packaging of the beauty products. We become pretty sure that our skin related problems would resolve. We get excited having seen before-and-after photos for any beauty service, it's simply more convincing. What we never What we never figure out is that skincare is certainly not a one-size-fits-all situation. In our research people don't visit a Salon regularly. It's only limited to occasions such as wedding. Very recently, from last 6-7 years it has been when our country has seen a change. People are becoming more conscious and caring about their looks and physical well-being. They have started to visit salon more frequently.

\section{Environmental impact of beauty industry}

Behind every glitz and glamour world, there is always a hideous and alluring visage of it. Beauty products beautify humans, but its effect on human health and environmental pollution is highly insidious now. The product and 
chemical composition of non-biodegradable toxic ingredients has justifiably got a bad rap for poor ecological pollution. Even though the whole beauty industry is estimated to grow to $\$ 820$ billion by 2023 , there is a steady growth in the harmful industrial chemicals used as cosmetic ingredients from 10,500. According to various reports, beauty products like cosmetics, nail polish, shampoo, and other personal care products contains chemical ingredients like sulphates, triclosan, lead, polyethene glycol (PEG), BHA and BHT, Oxybenzone etc., which lacks proper authentic data. These toxics are even linked to genital congenital disabilities in animals-even various epidemiologic studies conducted by WHO proved the cancer-causing abilities of these cosmetics.

The use of cosmetics from dependency is turning to an addiction which itself is an alarming point. It was beautifully quoted by one of our ancient Ayurvedas that the human body is a natural phenomenon and the skin problem one faces, the human body has the tendency to fight it and become stabilized again. But concocting the human body capacity with some external chemical (Cosmetics) would disturb the balance and instead of fixing the problem people may end up with side-effects. Use of cosmetics is not just dangerous to human bodies in the form of prolonged headaches, ageing, hair problems, lung disorders and even in some cases skin cancer but harms the environment too. According to recent surveys the Triclosan present in toothpastes and lipsticks once escapes through the sewage harms aquatic life. Obviously the amount of lead content in such products is immense which leads to lead poisoning with prolonged usage and finally the sprays we use are depleting the Ozone layer which ironically leads to skin cancer. Thanks to the hydrocarbons and Aerosol for being prime suspects.

Various cosmetics that are marketed under the "organic," "green", or "natural" labels, lacks laboratory evidence of their safety and authenticity. In fact, $89 \%$ of 10,500 ingredients used in personal care products have not been evaluated for safety by the CIR or anyone else (Sheikh, 2017). According to the Landmark report by BCPP, various harmful fragrance chemicals in beauty products are linked to environmental pollution and other birth defects, breast cancer, endocrine disruption in humans. Various volatile components in fragrances contribute to air pollution and smog. Also, the usage of palm oil leads to deforestation. While microbeads, microplastics, avobenzone in sunscreens, are now proven to deplete coral reefs. According to Zero Waste Europe, there is a prominent carbon footprint for beauty products, causing climate change and global warming.

Perhaps we should give more attention to the influence of the beauty brands we choose on the environment. According to reports, the worldwide cosmetics sector produces more than 120 billion units of packaging each year, much of which is not recyclable. The bulk of cosmetic products are wrapped in plastic, which takes over 1,000 years to disintegrate in the case of your ordinary moisturiser pot. Then there are the plastic wrappings, paper inserts, cardboard sleeves, foam, mirrored glass, and other accessories, which are sometimes all included in a single purchase. In landfills, this cosmetic packages might take hundreds of years to decompose. Toxic chemicals in cosmetics that are washed down drains wind up in oceans, causing environmental damage and the extinction of aquatic life. Toxins that wind up in the soil can cause reproductive, genetic, and developmental abnormalities in livestock, as well as a variety of cancers.

Cosmetic products are produced in different locations around the globe. For instance, France is the top exporter of Cosmetics in the world - a trade value of almost 20 billion dollars. And on the other side of the world, China is the 
largest market for French cosmetics. Similar trade channels all over the world require tremendous costs in aviation and shipping. The amount of CO2 produced by the aviation industry in 2019 alone was a whopping 915 million tonnes. In a world where celebrities generate more carbon footprint through their private jets, there are only a few exceptions like Keanu Reeves who is the torchbearer and the role model who takes fundamental steps in helping climate change and the environment. Keanu Reeves said "Environmental issues are on everyone's mind. It's part of our culture now and I can only applaud and laud anyone who is doing what they can and raising awareness." The world needs more of such individuals who practice what they preach. All these point to one alarming fact that the cosmetics industry is not regulated enough. Clearly, the industry is growing as people have more disposable income. But should their beauty come at the cost of our ecological survival?

Amarjit Sahota, president of Organic Monitor, spoke about cosmetics and sustainability at the Sustainable Cosmetics Summit in 2016: "There are no black-and-white solutions; rather, it's a balancing act with trade-offs." It is difficult to live a totally ethical and sustainable lifestyle as individuals. It's about accepting responsibility for doing our best to make ethical purchase selections. Then we may lessen and counteract our environmental impact by reusing and recycling. Naturally, when buying cosmetics, we can search for brands who are doing their best to conserve our beautiful planet by implementing programmes where they can.

When it comes to the greatest products with the best ingredients, the beauty business is undergoing huge transformations. Companies like Lush demonstrate that putting the environment first when it comes to cosmetics, soaps, and other important beauty goods is achievable. Their environmentally friendly green strategy is a leading industry standard, which includes never testing products on animals, avoiding the use of dangerous substances, limiting waste, and using energy efficiently

Beauty products are indeed precious to us. And anyone who claims differently may be in for a rude awakening. We want to smell and look good every day. And when we do, there's an inside and outward sensation of accomplishment. You only have to look at our strides to see how confident we are. These chemicals, unfortunately, are detrimental to both our bodies and the environment. Some of these poisonous goods are labelled with scientific symbols on the package. Worse, some are protected by "trade secret" laws, which prevent manufacturers from disclosing them. As a result, determining what these compounds are becomes extremely difficult. And, as a result, the extent to which they can affect our bodies. The issue is that we then develop cancer a few years later as a result of these toxins. While fashion has a horrible reputation for poor environmental standards, beauty pollution is far more insidious, despite its lower volume. Microbeads and microplastics, such as glitter, are impossible to remove from the ocean's surface.

As a conclusion, while the fight to protect the environment continues, you may make better choices with your choices. So, the next time you need a cosmetic product, go for the eco-friendlier products and do your part to help the earth. Reduce, reuse, and recycle can be applied to our beauty routines, and if enough people are more conscious of their product habits, the environment, plants, and animals will thrive, and we will as well. In the end, it can be concluded with a beautiful quote that the real beauty of a human is flawless and is hidden inside his/her own genuity and freshness. 


\section{Recommendations}

Our recommendations that the power of technology and the need for beauty enhancement procedures has given a tremendous push to aesthetic industry. It is ultimately going to be the change and future of beauty and wellness industry. The advent of specialized players, superspecialty areas, with skill fully trained aesthetics \& the best technological advances, will redesign a person's aesthetic experiences. These will easily differentiate themselves \& attain global acclaim, through their levels of expertise. Well qualified, experienced and licensed aesthetics will create better wellness infrastructure. A surge in demand for aesthetic services and products is sure to see a tremendous influx of ideas and techniques that will also provide something extra in terms of performance and results to customers.

So, our main focus on the Revamping or doing a makeover of beauty industry with respect to aesthetics. With this Mission To provide best products and services using the best and most advanced cutting-edge technologies, procured in a sustainable manner while respecting our environment, contributing to the well-being of our consumers and enriching their lives.

\section{Conclusion}

Cosmetics make you look good, but just like all things too good to be true, the positive benefits of using such products can take a toll on your health. In our survey People want to look beautiful and the concept of cosmetics is as old as mankind and development, but they need to beautify one's own body and look beautiful has been a desire in the human race since the tribal days. Since early days materials used for remodelling or improvement of presence comes under the category of cosmetics. Since long time cosmetics have been known to enhance the arrival of the human body. In our analysis it is clearly depicting that most of the respondents are accepting that the advertisements, which are shown to us are purely the signs of marketing gimmicks.

Also, we come to the conclusion of ratio of 2:1 from the data. In a society obsessed with beauty, people are lured to fake their appearance as a cure for their insecurities the average woman uses 12 personal care products a day containing 168 different chemicals. And from another analysis depicting that from 0-1 to more than 5-year respondents who have been taking services are depicting that salon is the only solution for the beauty services, and this can be shown in our above analysis. We come to the conclusion that they are only depend on the salon for their beauty services, they are not aware about the chemicals and harmful products used on them.

These products, which are imaginary to make us feel healthy and look beautiful, have a deep dark side. Various toxic ingredients and hazardous chemicals used in cosmetics are incorporated in beyond adequate limits. Cosmetics have not only seeped into the fashion world but are also playing a prominent role in one's day-to-day life.

Thus, it becomes a necessity to make people aware of various harmful effects of cosmetics and chemicals used in cosmetics. But our main emphasis is on the Revamping or doing a makeover of beauty industry with respect to aesthetics. With this Mission to provide best products and services using the best and most advanced cutting-edge technologies, procured in a sustainable manner while respecting our environment, contributing to the well-being of our consumers and enriching their lives. 


\section{Appendix}

\section{Questionnaire}

Gender

- Male

- Female

Age

- Below 16 years

- 16-30 years

- 31-45 years

- 46-60 years

- More than 60 years

How long have you been taking salon beauty services (such as facial, pedicure, manicure, hair colouring, keratin treatment, anti-aging, acne)?

- $0-1$ year

- 1-3 years

- 3-5 years

- More than 5 years

How often do you visit the beauty salon? (eg, once a week, twice a month)

Ans.

What kind of beauty services you generally have? (Multiple checkboxes)

- Hair treatment (like Scalp treatment, Protein or Keratin treatment of hairs)

- Hair steam/ deep-conditioning

- Hair perm/ Straightening

- Hair removal

- Hair dye/ color

- Hairstyle

- Beard trim

- Threading/ eyebrow and eyelashes extension or trimming 
- Makeup services: Party makeup

- Facials and clean up

- Body or skin treatment

- Manicure/ pedicure

- Massage

- Waxing

- Nail Extention/ art/ polishing

- Others, please specify

Do you have any perception of beauty salon before you render their services?

- Yes (Please specify )

- No

- Maybe

Is the advertisement that you see about natural herbals things are the market gimmicks or not for you?

- Yes

- No

Which of the following reason affect your choice of a beauty salon or reason for going to the salon? (Multiple answers can be given)

- Regular beauty rituals

- Salon as the only beauty service provider

- Staff knowledge and skill about the various salon services

- Quality of treatment

- Interior of the salon is designed according to consumer convenience

- Rapport with one or more member staff

- Awards and recognition salon have

- Free services like Refreshment offered in a salon

- The honesty of the salon

- Location of salon

- Payment system 


\section{AUAST}

- Clean, tidy and well-ventilated salon

- Equipped with a noticeable signboard

- Sufficient amount of staff

- Smooth service process

- Offer querying services and takes the appointment by phone

- Friendly, polite and service-minded staff

- Brand name, image, and reputation

- Prices are reasonable according to the product / service quality

- Services are according to international or government prescribed standards

- Recommendation from friends and family

- Discussion forums, beauty blogs

- Consumer ratings on the internet

- Website of the salon

- Customized packages

- Personal attention

- Status symbol

- Offers, discount coupons

- Magazine recommendation

- Advertisements

What is your reason for going to the salon?

- Habit

- Status symbol

- Special occasion

- Personal Hygiene

- Grooming

- Discount

- To enjoy self-time

- To feel relax 


\section{AJAST}

Asian Journal of Applied Science and Technology (AJAST)

Volume 5, Issue 3, Pages 162-176, July-September 2021

Are you satisfied with the Salon industry?

- Yes

- no

- maybe

if no, please specify

Your reason to biggest flaw of Salon industry

Ans.

\section{Declarations}

\section{Source of Funding}

This research did not receive any grant from funding agencies in the public, commercial, or not-for-profit sectors.

\section{Competing Interests Statement}

The authors declare no competing financial, professional and personal interests.

\section{Consent for publication}

Authors declare that they consented for the publication of this research work.

\section{References}

[1] Chemicals of concern. Campaign for safe cosmetics. Retrieved from (on November 25, 2019) http://www.safecosmetics.org/get-the-facts/chemof-concern.

[2] https://www.indiatoday.in/lifestyle/wellness/story/beauty-products-chemical-compositionskinharmful-effects-health-lifest-1022059-2017-07-03.

[3] (n.d.). Glameura - A Modern Platform to get Aesthetic and Beauty Services. https://glameura.com.

[4] (n.d.). Blu Ocean Studios Pvt. Ltd. https://www.bluoceanstudios.com.

[5] Rachna Jagia, MD, DNB, DAAAM-USA; head and senior consultant, Venkateshwar Hospital, Dwarka, (2017).

[6] Dr. Rohit Batra, dermatologist, Sir Ganga Ram Hospital, and Derma World Skin and Hair Clinic, (2017).

[7] Dr. Amit Bangia, consultant dermatologist, Asian Institute of Medical Sciences, (2017).

[8] (n.d.). Consultant firm | ESG | financial advisory services - PwC India.

[9] Health. (2019, 24). EY US - Building a better working world. https://www.ey.com/en_in/health. 